\title{
PURIFICATION AND CHARACTERIZATION OF SUCROSE SYNTHASE ISOZYMES FROM ETIOLATED RICE SEEDLINGS
}

\author{
Der-Yi Huang and Ai-Yu Wang* \\ Department of Agricultural Chemistry, National Taiwan University \\ No. 1 Section 4 Roosevelt Road, Taipei, Taiwan
}

Received April 4, 1998

Received after revision, May 11, 1998

SUMMARY Presence of homo- and hetero-tetrameric rice sucrose synthase (RSS) isoforms in etiolated rice seedlings was demonstrated by immunoprecipitation using monospecific antibodies. Three RSS isozymes with various pI values were purified by ammonium sulfate fractionation, Sepharose CL-6B gel filtration, DEAE-Sephacel and Mono-Q ion exchange chromatographies. They were characterized as heterotetramers composed of RSS1 and RSS2 subunits. All of them used UDP as the best substrate. The presence of divalent metal ions increased the activities of synthesis but inhibited the cleavage of sucrose.

Key Words: rice, sucrose synthase, isozymes, immunoprecipitation, purification

\section{INTRODUCTION}

Sucrose synthase (SS; UDPG:D-fructose 2-glucosyltransferase, E. C. 2.4.1.13) catalyzes the reaction of sucrose and UDP to form fructose and UDPG in plants. Although the reaction is readily reversible, it is thought that the enzyme functions primarily in the direction of sucrose degradation to provide sugar nucleotides for complex saccharides synthesis (1-4). In addition, SS is also known to play an important role in phloem loading and unloading of sucrose $(5,6)$.

SS has been characterized in various plant species since it was discovered by Cardini et al. (7). The native enzyme is a tetramer with molecular mass around $400 \mathrm{kD}$. In rice, $\mathrm{SS}$ is encoded by three differentially regulated genes, RSusl, RSus 2 , and $R S u s 3(8,9)$. The expression of RSus 1 and RSus 2 is ubiquitous in various rice tissues while that of $R S u s 3$ is exclusive in grains $(9,10)$. The presence of RSS isoforms has been found in rice grains at different stages of maturation (10) and four isozymes with various electrophoretic mobilities have been purified from milk-ripe grains (11). However, the structure and properties of the enzyme in other rice tissues remain uncharacterized. In the present study, we report the purification and characterization of three heterotetrameric isoforms of RSS encoded by RSus1 and RSus 2 in etiolated rice seedlings.

*To whom correspondence should be addressed. 


\section{METHODS}

\section{Plant materials and preparation of enzyme extract}

A japonica cultivar, Tainung 67, of Oryza sativa was used. Leaves of 8-day-old etiolated seedlings were ground to fine powder in liquid nitrogen. Precooled PB-7 (50 mM sodium phosphate buffer, pH 7.0, $1 \mathrm{mM}$ EDTA, $1 \mathrm{mM} \beta$-mercaptoethanol) was added and mixed. The supernatants following centrifugation at $12,000 \mathrm{~g}$ and $4{ }^{\circ} \mathrm{C}$ for $30 \mathrm{~min}$ were used for analysis and purification of RSS isozymes.

\section{Immunoprecipitation of RSS isozymes}

Monospecific antibodies (mAb) that only recognize RSus2-encoded RSS2 subunit were raised against a synthetic peptide containing 10 amino acid residues (CKQDSTYWDN) unique to the amino acid sequence of RSS2 (10). The specificity of the antibodies has been demonstrated by Western analysis using individual $R S u s$ gene products expressed in $E$. coli. (10). The monoclonal antibody for maize Susl-encoded SS2 was provided by Dr. P. S. Chourey. This antibody (designated as RSS1 mAb below) has been shown to neither crossreact with RSS2 nor RSS3 but specifically recognize RSS1 only (10, Wang, et al., submitted).

The crude extracts prepared from leaves of etiolated seedlings were mixed with either RSS1 or RSS2 $\mathrm{mAb}$. The antigen-antibody complexes were precipitated by Protein-A Sepharose CL-6B as described (12). After centrifugation, both the supernatants and pellets were subjected to Western analysis by two RSS mAbs.

\section{Purification of RSS isozymes}

All purification steps were carried out at $0-4{ }^{\circ} \mathrm{C}$. Nucleic acids in the crude enzyme extract were precipitated by adding protamine sulfate to a concentration of $0.2 \%$ and removed after centrifugation. Proteins fractionated by $35-65 \%$ saturation of ammonium sulfate were pelleted by centrifugation and dissolved in PB-7. The enzyme solution was applied onto a Sepharose CL-6B column $(2.6 \times 90 \mathrm{~cm})$ preequilibrated with PB-7. The column eluate containing SS activity was pooled and loaded onto a DEAE-Sephacel column. The column was first eluted with PB-7, then with a linear gradient from 0 to $0.3 \mathrm{M} \mathrm{NaCl}$ in PB-7. Further separation of various RSS isozymes was done by loading the enzyme solution onto a FPLC Mono-Q column and a gradient of $0.08 \sim 0.25 \mathrm{M} \mathrm{NaCl}$ in PB-7 was applied. Three SS peaks were obtained. The fraction with the highest SS activity in each peak was stored at $-20{ }^{\circ} \mathrm{C}$ individually after dialysis against PB-7.

\section{Enzyme Assay and Protein Determination}

The sucrose cleavage and synthetic activities of RSS were assayed as described by Su $e t$ al. (13) and Klann et al. (14), respectively. The nucleotide specificity of the enzyme was determined as reported (11). The protein content of enzyme solutions was determined by the Bradford's method (15) using bovine serum albumin as the standard.

\section{Polyacrylamide Gel Electrophoresis and Western analysis}

Proteins were separated by $10 \%$ SDS-PAGE according to the method of Laemmli (16). Western analysis was done as described (17). For determining the pI values of each RSS isozymes, the Immobiline DryPlate (pH 4.0 - 7.0, from Pharmacia) was rehydrated according to the manufacture and isoelectric focusing (IEF) was performed at constant voltage of $2500 \mathrm{~V}$ at $4{ }^{\circ} \mathrm{C}$ for $7 \mathrm{~h}$. The protein bands were stained with Coomassie Blue R-250. 


\section{RESULTS}

\section{Identification of RSS isoforms in etiolated rice seedlings}

Presence of RSS isoforms in rice seedlings was demonstrated by immunoprecipitation experiments using an antibody monospecific to RSus1-encoded RSS1 or RSus2-encoded RSS2. Fig. 1 shows the Western analysis of the enzyme in the supernatants and precipitates after immunoprecipitation and centrifugation. Although the antibody used for precipitation was monospecific to RSS1, we observed the presence of RSS2 proteins in the precipitates as analyzed by RSS2 mAb. It indicated that the heterotetrameric RSS composed of RSS1 and RSS2 subunits was in the enzyme extract of rice seedlings. The enzyme remained in the supernatants (Fig. 1A) could only be detected by RSS2 mAb, suggesting the presence of homotetrameric RSS2 but in small amount. The immunoprecipitation experiments with RSS2 mAb gave similar result (data not shown).

\section{Purification and characterization of RSS isozymes from etiolated rice seedlings}

Through the sequential steps of enzyme purification described above, three RSS isozymes (designated as RSSI, RSSII, and RSSIII) could be separated (Fig. 2A). When examined on SDS-PAGE, only a single major band was seen in the RSSII and RSSIII preparations (Fig. 2B, lanes 4 and 5). Several minor bands were observed in RSSI (Fig. 2B, lane 1). However, some of them were degraded from the major band as analyzed by Western blotting (data not shown). All of the enzymes could be detected by RSS1 and RSS2 mAb in Western analyses (data not shown), suggesting that the three isozymes might be composed of both RSS1 and RSS2 subunits. The specific activities in sucrose cleavage reaction were 2.73, 6.35 and 5.05 units/mg protein for RSSI, RSSII and RSSIII, respectively.

Both RSSII and RSSIII showed a single band on the IEF gel (Fig. 3). The diffused protein bands on the gel were resulted from the tendency of the enzyme to precipitate at the $\mathrm{pH}$

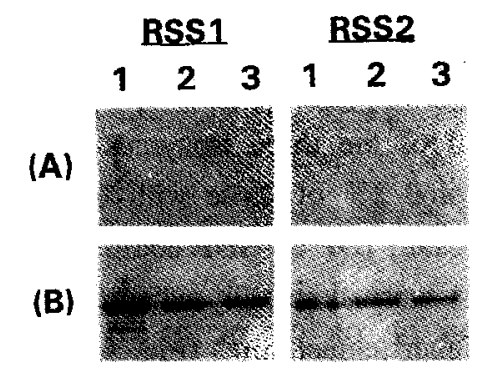

Fig. 1. Identification of RSS isoforms in etiolated rice seedlings. 80,40 and $20 \mu \mathrm{g}$ (lanes 1,2 and 3 , respectively) of total proteins were incubated with RSS1 mAb and Protein-A Sepharose. After centrifugation, both the supernatants (A) and pellets (B) were subjected to Western analyses by RSS1 and RSS 2 mAbs. 


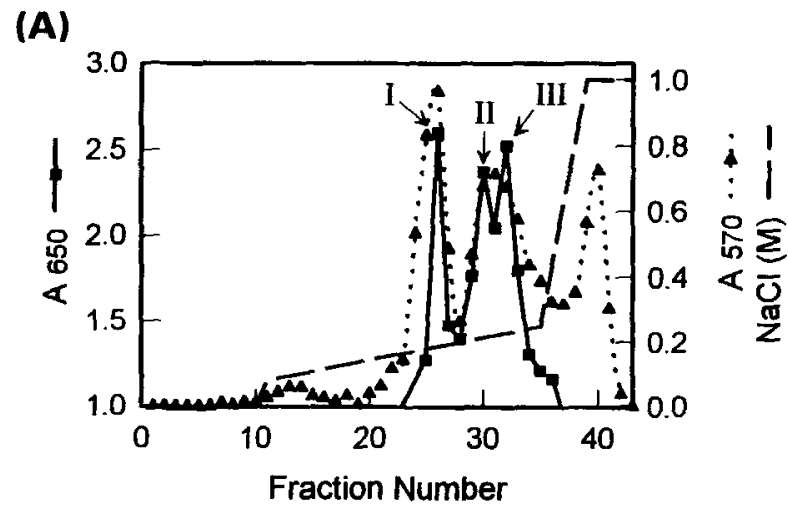

(B)

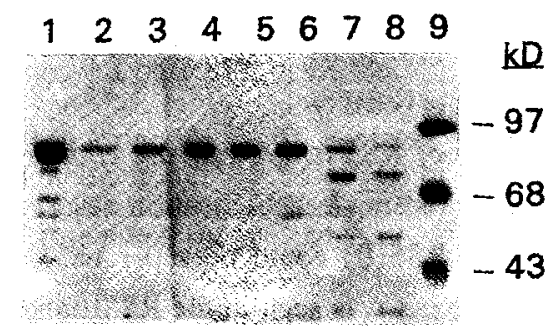

Fig. 2. Purification of RSS isozymes. Panel A: The Mono-Q ion exchange chromatogram. The enzyme activity was assayed in the direction of sucrose synthesis (A650). The protein concentrations were determined by the Bradford's method (A570). The fractions with the highest activity in the three SS peaks were designated as RSSI, RSSII and RSSIII (fractions 26, 30 and 32, indicated by arrows). Panel B: SDS-PAGE of various fractions in A. The samples loaded in lanes 1 to 8 contained about $13,3,5,7,7,6,4$ and $3 \mu \mathrm{g}$ of proteins in $10 \mu \mathrm{L}$ from fractions $26,28,29,30,32,33,34$ and 36, respectively. Lane 9 is the standard molecular mass.

near pI value. The pI values were estimated as 5.6, and 5.5 for RSSII and RSSIII, respectively. The pI value of RSSI was higher than those of RSSII and RSSIII. However, the protein band was broad, suggesting that the enzyme preparation was not homogeneous. In the cleavage reaction of sucrose, all of the three isozymes used UDP as the best substrate. Activities with ADP were 6, 4 and $2 \%$ of those with UDP for RSSI, RSSII and RSSIII, respectively. Reactivity toward CDP, IDP or GDP could not be detected. Among the three isozymes, RSSIII showed the best thermal stability when temperatures were below $45^{\circ} \mathrm{C}$ but lost its activity most rapidly at higher temperatures (Fig. 4). The presence of $\mathrm{Mg}^{2+}$ and $\mathrm{Ca}^{2+}$ ions has opposite effects on the sucrose cleavage and synthesis activity of the three isozymes (Table 1). 


\section{DISCUSSION}

Although SS has been characterized in rice for years by several studies (11, 17-20), this is the first report demonstrating the presence of both homo- and hetero-tetrameric RSS isozymes in rice seedlings by immunoprecipitation and enzyme purification. The major forms of the enzyme in rice seedlings are heterotetramers, suggesting the coexpression of RSus1 and RSus2 genes in the same cellular compartments.

Purification of RSS isozymes from rice seedlings was a challenge because of the high degree of sequence homology and small differences in the size $(<1 \%)$ of protomers, and the isozymes exhibit the same electrophoretic mobility on the native PAGE $(9,10)$. In this study, we found that the successful separation of the three heterotetrameric RSS isoforms could not be

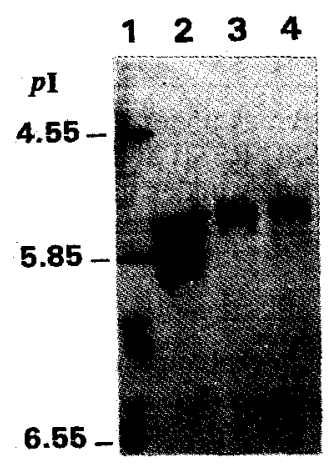

Fig. 3. Determination of pI values of RSS isozymes by isoelectric focusing. $120 \mu \mathrm{g}$ of RSSI (lane 2) and $60 \mu \mathrm{g}$ of RSSII (lane 3) and RSSIII (lane 4) were loaded. Lane 1 is the standard proteins with known $\mathrm{pI}$ values

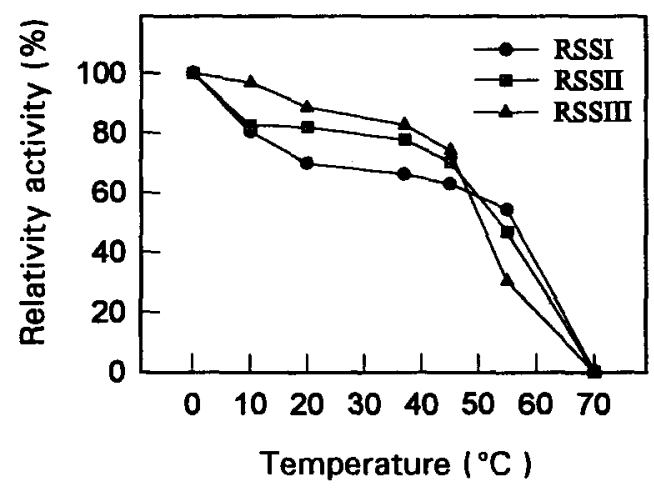

Fig. 4. Thermal stability of RSS isozymes. The purified enzymes ( $48 \mu \mathrm{g}$ of RSSI, $22 \mu \mathrm{g}$ of RSSII and RSSIII) were incubated in $0.1 \mathrm{~mL} \mathrm{PB-7}$ at various temperatures for $15 \mathrm{~min}$. The residual enzyme activity was assayed in the direction of sucrose cleavage. 
Table 1. Effects of divalent ions on the activity of RSS isozymes

\begin{tabular}{|c|c|c|c|c|c|c|}
\hline \multirow{3}{*}{$\begin{array}{l}\text { Addition } \\
\text { (mM) }\end{array}$} & \multicolumn{6}{|c|}{ Relative Activity (\%) } \\
\hline & \multicolumn{3}{|c|}{ Sucrose cleavage* } & \multicolumn{3}{|c|}{ Sucrose synthesis" } \\
\hline & RSSI & RSSII & RSSIII & RSSI & RSSII & RSSIII \\
\hline \multicolumn{7}{|l|}{$\mathrm{CaCl} 2$} \\
\hline 0 & 100 & 100 & 100 & 100 & 100 & 100 \\
\hline 2.5 & 89 & 95 & 91 & 148 & 114 & 119 \\
\hline 5 & 88 & 93 & 90 & 152 & 121 & 117 \\
\hline 10 & 91 & 92 & 88 & 188 & 117 & 118 \\
\hline \multicolumn{7}{|l|}{$\mathrm{MgCl} 2$} \\
\hline 0 & 100 & 100 & 100 & 100 & 100 & 100 \\
\hline 2.5 & 82 & 93 & 83 & 132 & 118 & 113 \\
\hline 5 & 82 & 88 & 86 & 143 & 139 & 115 \\
\hline 10 & 83 & 92 & 79 & 166 & 129 & 126 \\
\hline
\end{tabular}

*The specific activities of the enzymes under the control conditions were $2.7,6.4$ and 5.1 units/mg protein for RSSI, RSSII and RSSIII, respectively.

${ }^{*}$ The specific activities of the enzymes under the control conditions were 5.7, 20.4 and 12 units/mg protein for RSSI, RSSII and RSSIII, respectively

achieved without the final Mono-Q ion exchange chromatography. However, we have not obtained the homotetrameric forms of RSS yet. It may be due to the low concentration of homotetrameric RSS in the extract of rice seedlings and their activities were easily ignored during the purification. The purified heterotetrameric RSS isozymes show similar activity in sucrose cleavage (data not shown) but the specific activity of RSSI was lower than those of the other two isoforms. It may result from the copurification of other proteins with RSSI as judged from the IEF gel. The three RSS isoforms possess similar general biochemical properties except $\mathrm{pI}$ values (RSSI $>$ RSSII $>$ RSSIII). The $\mathrm{pI}$ values calculated from the amino acid sequences that are deduced from RSus 1 and RSus 2 cDNA (9) are 6.17 and 5.92 for RSS1 and RSS2 isoforms, respectively. Therefore, we postulate that the possible quaternary structures for RSSI, RSSII, and RSSIII are (RSS1) $_{3}(\mathrm{RSS} 2)_{1}, \quad(\mathrm{RSS1})_{2}(\mathrm{RSS} 2)_{2}$, and (RSS1 $)_{1}(\mathrm{RSS} 2)_{3}$, respectively. It was shown that the expressions of $R S u s 1$ and $R S u s 2$ in rice seedlings are complementary each other under some physiological stresses $(9,10)$. Therefore, presence of various isoforms of RSS may be important in response to environmental changes to ensure the housekeeping function of rice plants.

\section{ACKNOWLEDGMENT}

We thank Dr. P. S. Chourey for providing maize SS monoclonal antibodies and Dr. J.-C. Su for reading this manuscript. This work was supported by a grant from the National Science Council, Republic of China. 


\section{REFERENCES}

1. Chourey, P. S., and Nelson, O. E. (1976) Biochem. Genet. 14, 1041-1055.

2. Chourey, P. S., Chen, Y. C., and Miller, M. E. (1991) Maydica 36, 141-146.

3. Amor, Y., Haigler, C. H., Johnson, S., Wainscott, M., and Delmer, D. P. (1995) Proc. Natl. Acad. Sci. USA 92, 9353-9357.

4. Carlson, S. J., and Chourey, P. S. (1996) Mol. Gen. Genet. 252, 303-310.

5. Geigenberger, P., and Stitt, M. (1993) Planta 189, 329-339.

6. Martin, T., Frommer, W. B., Salanoubat, M., and Willmitzer, L. (1993) Plant J. 4, 367377.

7. Cardini, C. E., Leloir, L. F., and Chiriboga, J. (1955) J. Biol. Chem. 214, 149-155.

8. Wang, A.-Y., Yu, W.-P., Juang, R.-H., Huang, J.-W., Sung, H.-Y., and Su, J.-C. (1992) Plant Mol. Biol. 19, 881-885.

9. Huang, J.-W., Chen, J.-T., Yu, W.-P., Shyur, L.-F., Wang, A.-Y., Sung, H.-Y., Lee, P.D., and Su, J.-C. (1996) Biosci. Biotech. Biochem. 60, 233-239.

10. Kao, M.-H. (1996) Master Thesis, National Taiwan University, Taipei, Taiwan.

11. Yen, S.-F., Su, J.-C., and Sung, H.-Y. (1994) Biochem. Mol. Biol. Int. 34, 613-620.

12. Mann, K., Hunter, T., Walter, G., and Linke, H. K. (1977) J. Virol., 24, 151-169.

13. Su, J.-C., Wu, J.-L., and Yang, C.-L. (1977) Plant Physiol. 60, 17-21.

14. Klann, E. M., Chetelat, R. T., and Bennett, A. B. (1993) Plant Physiol. 103, 863-870.

15. Bradford, M. M. (1976) Anal. Biochem. 59, 248-254.

16. Laemmli, U. K. (1970) Nature 227, 680-685.

17. Juang, R.-H., and Su, J.-C. (1988) J. Chin. Biochem. Soc. 17, 42-51.

18. Nomura, T., and Akazawa, T. (1973) Arch. Biochem. Biophy. 156, 644-652.

19. Chan, H. Y., Ling, T. Y., Juang, R. H., Ting, I. N., Sung, H. Y., and Su, J. C. (1990) Plant Physiol. 94, 1456-1461.

20. Elling, L., and Kula, M.-R. (1993) J. Biotech. 29, 277-286. 